Primary Health Care

Research \& Development

\section{cambridge.org/phc}

\section{Development}

Cite this article: Hadziabdic E, Pettersson S, Marklund H, Hjelm K. (2020) Development of a group-based diabetes education model for migrants with type 2 diabetes, living in Sweden. Primary Health Care Research \& Development 21(e50): 1-8. doi: 10.1017/S1463423620000493

Received: 3 March 2020

Revised: 9 September 2020

Accepted: 13 October 2020

\section{Key words:}

culturally appropriate health diabetes education model; migrants; type 2 diabetes

\section{Author for correspondence:}

Professor Katarina Hjelm, Department of Public Health and Caring Sciences, Uppsala University, P.O. Box 564, S-751 22 Uppsala, Sweden. E-mail:

katarina.hjelm@pubcare.uu.se

\title{
Development of a group-based diabetes education model for migrants with type 2 diabetes, living in Sweden
}

\section{Emina Hadziabdic ${ }^{1}$, Sara Pettersson ${ }^{2}$, Helén Marklund ${ }^{2}$ and Katarina Hjelm ${ }^{3}$ (B)}

${ }^{1}$ Department of Health and Life Sciences, Linnaeus University, Växjö, Sweden; ${ }^{2}$ Department of Social and Welfare Studies, Linkoping University, Norrköping, Sweden and ${ }^{3}$ Department of Public Health and Caring Sciences, Uppsala University, Uppsala, Sweden

\begin{abstract}
Aim: To develop a diabetes education model based on individual beliefs, knowledge and risk awareness, aimed at migrants with type 2 diabetes, living in Sweden. Background: Type 2 diabetes is rapidly increasing globally, particularly affecting migrants living in developed countries. There is ongoing debate about what kind of teaching method gives the best result, but few studies have evaluated different methods for teaching migrants. Previous studies lack a theoretical base and do not proceed from the individuals' own beliefs about health and illness, underpinned by their knowledge, guiding their health-related behaviour. Methods: A diabetes education model was developed to increase knowledge about diabetes and to influence self-care among migrants with type 2 diabetes. The model was based on literature review, on results from a previous study investigating knowledge about diabetes, on experience from studies of beliefs about health and illness, and on collaboration between researchers in diabetes care and migration and health and staff working in a multi-professional diabetes team. Findings: This is a culturally appropriate diabetes education model proceeding from individual beliefs about health and illness and knowledge, conducted in focus-group discussions in five sessions, led by a diabetes specialist nurse in collaboration with a multi-professional team, and completed within three months. The focus groups should include 4-5 persons and last for about $90 \mathrm{~min}$, in the presence of an interpreter. A thematic interview guide should be used, with broad open-ended questions and descriptions of critical situations/health problems. Discussions of individual beliefs based on knowledge are encouraged. When needed, healthcare staff present at the session answer questions, add information and ensure that basic principles for diabetes care are covered. The diabetes education model is tailored to both individual and cultural aspects and can improve knowledge about type 2 diabetes, among migrants and thus increase self-care behaviour and improve health.
\end{abstract}

(c) The Author(s) 2020. This is an Open Access article, distributed under the terms of the Creative Commons Attribution licence (http:// creativecommons.org/licenses/by/4.0/), which permits unrestricted re-use, distribution, and reproduction in any medium, provided the original work is properly cited.

\section{CAMBRIDGE} UNIVERSITY PRESS

\section{Background and rationale for the development}

Diabetes Mellitus (DM) is rapidly increasing globally, predominantly including type 2 diabetes (85\%) and particularly affecting migrants living in developed countries (IDF, 2017; Cho et al., 2018). At the same time, this group shows difficulties in assimilating knowledge about diabetes and self-management through the education that is usually offered at diabetes clinics (Testa et al., 2015). The growing burden of type 2 diabetes among foreign-born persons represents a serious public health challenge for many European countries (Montesi et al., 2016). The ongoing migration is not expected to slow down and will generate increasing economic costs for several European national health systems (Montesi et al., 2016), and cause suffering for the individual (IDF, 2017).

Active participation in self-care, based on knowledge about the disease, is the most important cornerstone for a person's self-management of type 2 diabetes (Testa et al., 2015; IDF, 2017; Socialstyrelsen, 2018; ADA, 2019). Thus, education should enhance a patient's knowledge and skills regarding the management and empower them to take an active role in their treatment (Coppola et al., 2016; Chatterjee et al., 2018; ADA, 2019; Miller et al., 2020), aiming to achieve good glycaemic control to prevent diabetes-related complications (Testa et al., 2015; IDF, 2017; Socialstyrelsen, 2018). There is ongoing debate about what kind of teaching method gives the best result, but few studies have evaluated different methods for teaching migrant groups or ethnic minority groups (Hawthorne et al., 2008; Socialstyrelsen, 2012; 2018). The Diabetes Education and Self-Management for Ongoing and Newly Diagnosed (DESMOND) programme is a structured group-based educational programme for people with type 2 diabetes (run since 2008). It is used in the UK (Chatterjee et al., 2018) and Australia (Miller et al., 2020) and is one of the only programmes that have been extensively evaluated to show a variety of health outcome improvements. Some courses in the programme have been adapted for delivery to South Asian 
ethnic populations but the impact on ethnic minority groups needs to be evaluated (Chatterjee et al., 2018).

Previous qualitative studies, comparing foreign- and Swedishborn persons with type 2 diabetes living in Sweden, indicated dissimilarities, with foreign-born persons (migrants) having limited knowledge about diabetes and underestimating the seriousness of diabetes, compared to Swedes; this affected self-care behaviour (Hjelm et al., 1999; 2003; 2005; 2013). A previous study (Pettersson et al., 2018), measuring knowledge about diabetes, confirmed the hypothesis. In addition, the results showed that persons originating from non-European countries had the lowest level of knowledge about diabetes.

It is a challenge to understand the complex process of self-care and to develop appropriate education models that support patients in managing their chronic illness and maintaining or improving their health (ADA, 2019). Criticism of normal diabetes care, including education about diabetes, has emphasised the lack of patient involvement and the focus on control, instead of patient-centredness (Hörnsten and Graneheim, 2009). Education has been recognised as an essential aspect of care for diabetes by improving knowledge about the disease and thus enhancing the patient's self-care and improving health outcomes (Coppola et al., 2016; Chatterjee et al., 2018; ADA, 2019; Miller et al., 2020). It is therefore important to examine what kind of education is most appropriate.

Normal care visits are often not culturally or individually adapted, in contrast to what is recommended (Socialstyrelsen, 2012; 2018). It is important to remember that one of the nurse's main tasks is to support patients in self-care by teaching why assessment of knowledge about the disease is important (Leininger and McFarland, 2006). Thus, the implementation of interventions to improve knowledge about diabetes for persons with established diabetes should become a public health priority across the world (IDF, 2017).

Today, diabetes care in Sweden should be and is recommended to be based on the national guidelines for diabetes care (Socialstyrelsen, 2018). The majority of patients diagnosed with type 2 diabetes are managed in health care centres in primary health care, but patients with severe type 2 diabetes and with complications related to diabetes are managed by specialists at in-hospital diabetes clinics for adults. The ambition of Swedish diabetes care is to work in multi-professional teams (Socialstyrelsen, 2018). At the primary health care clinic, the patient should be managed by a team including a general practitioner (GP) particularly trained in diabetes management, a diabetes specialist nurse and if needed a podiatrist, a physiotherapist and a social worker. A GP and a diabetes specialist nurse should meet each patient at least once a year, and focus on quality of care documents, such as national guidelines and the national diabetes register. Other professionals should also meet the patient when there is a need. Together with the patient, targets for treatment are set, which are based on assessment of quality of life and the risk of complications. The aim is to achieve good results for the patient. It should be clarified that the patient must take great responsibility for self-care. Even though a multi-professional team is recommended, the reality often means that there is only a GP and a diabetes specialist nurse in the team, while the other professionals work on a consultancy basis (Socialstyrelsen, 2012; 2018).

Group-based diabetes education and culturally adapted diabetes education is recommended for persons diagnosed with type 2 diabetes, including migrants (SBU, 2009; Socialstyrelsen, 2012; 2018), but is scarce in Swedish diabetes care. Educational models are lacking.
Cultural tailoring is a concept that utilizes the understanding of the effects of cultural characteristics on health behaviours to design a useful intervention (Hawthorne et al., 2008; Attridge et al., 2014). Culturally appropriate health education can be defined as education that is tailored to the cultural and religious beliefs and linguistic skills of the targeted community, but also taking literacy skills into consideration (Attridge et al., 2014). Even though research activity in this field has increased over the last decade, showing that culturally appropriate diabetes education yields consistent benefits over conventional care in terms of improved glycaemic control and diabetes knowledge, there is a need for further studies to investigate successful aspects of culturally tailored education models for migrants with type 2 diabetes and to develop new models for diabetes education to be tested in order to determine their clinical significance (Hawthorne et al., 2008; Attridge et al., 2014; Chatterjee et al., 2018). Previous investigations focussing on culturally appropriate education (Hawthorne et al., 2008; Attridge et al., 2014; Creamer et al., 2016) have mainly focussed on ethnic minorities in the US, showing that many lack a theoretical base and a definition of the concept. They have been implemented with preplanned structured lectures, where the educator, usually a healthcare professional, teaches the patient about diabetes care, and does not proceed from the individuals' own beliefs about health and illness, underpinned by their knowledge and guiding their health-related behaviour.

The aim is to develop a diabetes education model for migrants with type 2 diabetes living in Sweden, based on individual beliefs, knowledge and risk awareness.

\section{Development of the model}

This article describes the development of a diabetes education model for migrants aimed to be used in an intervention study to increase knowledge about diabetes and thus influence self-care among migrants with type 2 diabetes. In developing complex interventions in health it is important to construct a model of the intervention, based on existing data and similar interventions and an idea of the theory behind the proposed interventions as the first step (Richards, 2015).

The development work for the education model started in June 2014 and ended in April 2017. The model is based on a review of literature, a previous study (Pettersson et al., 2018) investigating knowledge about diabetes, and experiences from previous research on beliefs about health and illness (Hjelm et al., 1999; 2003; 2005; 2013). It was developed in collaboration between researchers experienced in diabetes care and migration and health, and staff working in a multi-professional diabetes team. The diabetes team worked at a diabetes clinic in a primary health care centre in an area of Sweden where a fifth of the population was born abroad (Statistiska Centralbyrån, 2018).

Literature was searched in PubMed, Cinahl and Cochrane Library, as well as governmental reports from the National Board of Health and Welfare, the Swedish Agency for Health Technology Assessment and Assessment of Social Services and national guidelines for diabetes care, particularly in the following areas: culturally adapted diabetes education for foreign-born persons diagnosed with type 2 diabetes, development of education models, pedagogical methods and diabetes and diabetes care. References in recently published studies were scrutinised and chain searching by hand was also performed. Discussions were held with front-line researchers regarding key references. 
From the previous study (Pettersson et al., 2018) knowledge gaps concerning diabetes could be identified. Experiences from qualitative research using focus-group interviews to investigate beliefs about health and illness (Hjelm et al., 1999; 2003; 2005; 2013) were drawn on to develop the instrument (an interview guide) for the focus-group discussions in the proposed programme following the research.

Finally, the results were discussed between the researchers and the multi-professional diabetes team, including a diabetes specialist nurse, a general practitioner, a podiatrist and a dietician, working in a migrant-dense area in Sweden. All those involved had expertise in diabetes education and patient education. Clinical experiences could thus be taken into consideration and reflected upon in a theoretical framework.

\section{Diabetes education model for migrants with type 2 diabetes}

In summary, this education model is planned to be culturally appropriate diabetes education conducted in focus-group discussions proceeding from the person's individual beliefs about health and illness based on the person's knowledge. The diabetes education should be held at a primary health care centre and implemented by a multiprofessional diabetes team, led by a nurse specialised in diabetes care, assisted by an interpreter. The focus-group discussions are guided by a thematic semi-structured interview guide. The model is planned to include five sessions, each one approximately $90 \mathrm{~min}$ long, and the education should be completed in three months. The evidence for this is presented in the text below and the model is described in Table 1.

\section{The culturally appropriate education diabetes model based on the person's individual beliefs about health and illness and the person's knowledge}

The theoretical framework for this model is that culturally appropriate diabetes education is defined as education that takes into account cultural and religious perceptions as well as language, providing information to same-gender groups and also adapting food advice to suit the particular community (Attridge et al., 2014). Thus, the model is planned to be tailored to the patients' beliefs and understanding and aimed to develop awareness of the seriousness of the condition in order to influence self-care behaviour (Hjelm et al., 1999; 2003; 2005; 2013). Individual beliefs about health and illness are based on knowledge, and constitute attitudes towards health-related behaviour, including self-care, which they guide (see Figure 1) (Hjelm et al., 1999; 2003; 2005; 2013; Glanz et al., 2008). The health belief model (HBM; Rosenstock et al., 1988), including perceived threat, seriousness of and susceptibility to a disease, and degree of self-efficacy (Bandura, 1995), can explain health-related behaviour. A high level of self-efficacy (confidence) contributes to active behaviour and has been shown to be increased by knowledge gained from structured diabetes education in groups (Chatterjee et al., 2018; Miller et al., 2020). This leads to better health outcomes and well-being.

Individual beliefs are culturally determined, transmitted through language and learned by socialisation and contact with others in the family, other groups and institutions in society (e.g. schools, churches, health care institutions) (Berger and Luckmann, 1991). Thus the health care education should be individualised, taking account of cultural differences. The advice and recommendations given should, as far as possible, be adapted to the patient's individual beliefs, needs and wishes (Hjelm et al., 1999; $2003 ; 2005 ; 2013$ ) as stated in the laws guiding healthcare (SFS,
2014; 2017). Health education, according to educational theory, should be implemented in a learner-centred manner respecting cultural, social and religious values to have the greatest impact (Rogers and Freiberg, 1994; Knight et al., 2006). The role of the healthcare staff is to facilitate learning by eliciting the person's individual beliefs, stimulating interaction/discussions and supporting with information if needed. The participant (patient) is the expert on their health and should be in the centre.

In summary, previous systematic reviews (Hawthorne et al., 2008; Attridge et al., 2014; Creamer et al., 2016) found that culturally appropriate diabetes education showed consistent benefits over conventional care in terms of glycaemic control and diabetes knowledge, sustained in the short to mid-term.

\section{Educational method}

To reach the participants' individual beliefs, a teaching strategy based on focus-group interviewing technique was chosen (Krueger and Casey, 2015). Guided by a skilled interviewer, the participants share their ideas, beliefs and experiences, influencing each other by responding to ideas and comments in the discussions. Through the interaction in the groups, the participants' thoughts will get carried away by the discussions and thus more or less conscious beliefs will be revealed (Tang and Davis, 1995; Krueger and Casey, 2015).

The aim of focus groups is to listen and gather information and opinions from participants (Krueger and Casey, 2015). The method is particularly useful for exploring people's knowledge and experiences about a subject and investigating why they think in a certain way and how they act (Kitzinger, 1995). Here the aim is: (a) to better understand patients' own beliefs about health and illness; (b) to understand how the respondents feel or think about diabetes and diabetes care; (c) to facilitate learning by using the group interaction and (d) to let the participants share their experiences of living with the chronic disease in order to learn to cope with it (Hjelm et al., 2003; 2005; 2013; Krueger and Casey, 2015).

During the different sessions, the participants are asked to discuss experiences of certain themes or in relation to critical situations/health problems described in the respective sessions concerning diabetes and self-care. The participants respond to open-ended questions, posed by a moderator, the nurse specialised in diabetes care, who leads the discussion in the group. The focus for the nurse and moderator is to create a welcoming environment for the participants that encourages them to share their understanding and experiences, and promote an equal environment without letting any participant become dominant in the group (Krueger and Casey, 2015). In addition to the nurse, an interpreter should be present at all sessions, and at each session one of the diabetes team members - the nurse, the podiatrist, the physician, or the dietician - will attend, linked to their particular area of competence. At the last session all members of the diabetes team participate.

To facilitate the discussions, an interview guide is used, with broad questions and descriptions of critical situations/health problems, encouraging discussions of individual beliefs. The areas in the interview guide and thus the themes for the different sessions are presented in Table 1.

Previous research has found that education models should be tailored to the patient's individual beliefs and aimed to develop awareness of the seriousness of the disease (Hjelm et al., 2003; 2005). When needed healthcare staff present at the sessions answer questions raised during the discussions, explain certain issues to the participants and ensure that basic principles of diabetes care 
Table 1. Overview of the sessions in the diabetes education model

\begin{tabular}{|c|c|c|c|c|c|}
\hline Session & 1 & 2 & 3 & 4 & 5 \\
\hline $\begin{array}{l}\text { Theme for discus- } \\
\text { sion, content }\end{array}$ & $\begin{array}{l}\text { Individual beliefs about illness; why } \\
\text { they got diabetes, how it was discov- } \\
\text { ered, how it might affect the body, } \\
\text { normal glucose uptake, and beliefs } \\
\text { about future health and fears related } \\
\text { to diabetes. }\end{array}$ & $\begin{array}{l}\text { Individual beliefs about how to } \\
\text { achieve good glycemic control to } \\
\text { maintain health and how to recog- } \\
\text { nise changes in blood glucose. } \\
\text { Self-care measures and medica- } \\
\text { tions focussed. }\end{array}$ & $\begin{array}{l}\text { Individual beliefs about why } \\
\text { diabetes-related short- and } \\
\text { long-term complications } \\
\text { occur, how they affect the } \\
\text { body and how they can be } \\
\text { prevented to promote and } \\
\text { maintain health. Focus on } \\
\text { daily foot care and preven- } \\
\text { tion of 'the diabetic foot'. }\end{array}$ & $\begin{array}{l}\text { Individual beliefs about } \\
\text { diet and eating habits } \\
\text { and basic principles for } \\
\text { dietary adjustment to } \\
\text { achieve good glycemic } \\
\text { control. }\end{array}$ & $\begin{array}{l}\text { Summarising individual beliefs about } \\
\text { how to achieve good glycemic control } \\
\text { through the complex relation between } \\
\text { diet, exercise, medications and aware- } \\
\text { ness/knowledge and answering partici- } \\
\text { pants' questions. }\end{array}$ \\
\hline \multirow[t]{4}{*}{ Staff attending } & $\begin{array}{l}\text { Diabetes specialist nurse, leader of the } \\
\text { session }\end{array}$ & $\begin{array}{l}\text { Diabetes specialist nurse, leader of } \\
\text { the session }\end{array}$ & $\begin{array}{l}\text { Diabetes specialist nurse, } \\
\text { leader of the session }\end{array}$ & $\begin{array}{l}\text { Diabetes specialist } \\
\text { nurse, leader of the ses- } \\
\text { sion }\end{array}$ & $\begin{array}{l}\text { Diabetes specialist nurse, leader of the } \\
\text { session }\end{array}$ \\
\hline & Interpreter & Interpreter & Interpreter & Interpreter & Interpreter \\
\hline & & Physician - GPa & & Dietician & Dietician \\
\hline & & & & & Physician - GPa \\
\hline Venue & \multicolumn{5}{|c|}{ Diabetes clinic in a primary healthcare centre } \\
\hline Teaching method & \multicolumn{5}{|c|}{$\begin{array}{l}\text { Focus-group interviews, to reach individual beliefs about health and illness, based on knowledge, determining health-related behaviour. A thematic interview guide, with open-ended } \\
\text { questions and critical situations/health problems described, to facilitate interaction/discussions. Knowledge gaps or irrelevant beliefs disclosed to be discussed and content related to } \\
\text { main principles for diabetes care. }\end{array}$} \\
\hline Group size & \multicolumn{5}{|l|}{ 4-5 participants/group } \\
\hline Length of session & \multicolumn{5}{|l|}{ About $90 \mathrm{~min} / \mathrm{session}$} \\
\hline Time planning & & Two weeks after first session & Four weeks after first session & $\begin{array}{l}\text { Eight weeks after first } \\
\text { session }\end{array}$ & Twelve weeks after first session \\
\hline Total duration & & & & & About three months \\
\hline
\end{tabular}




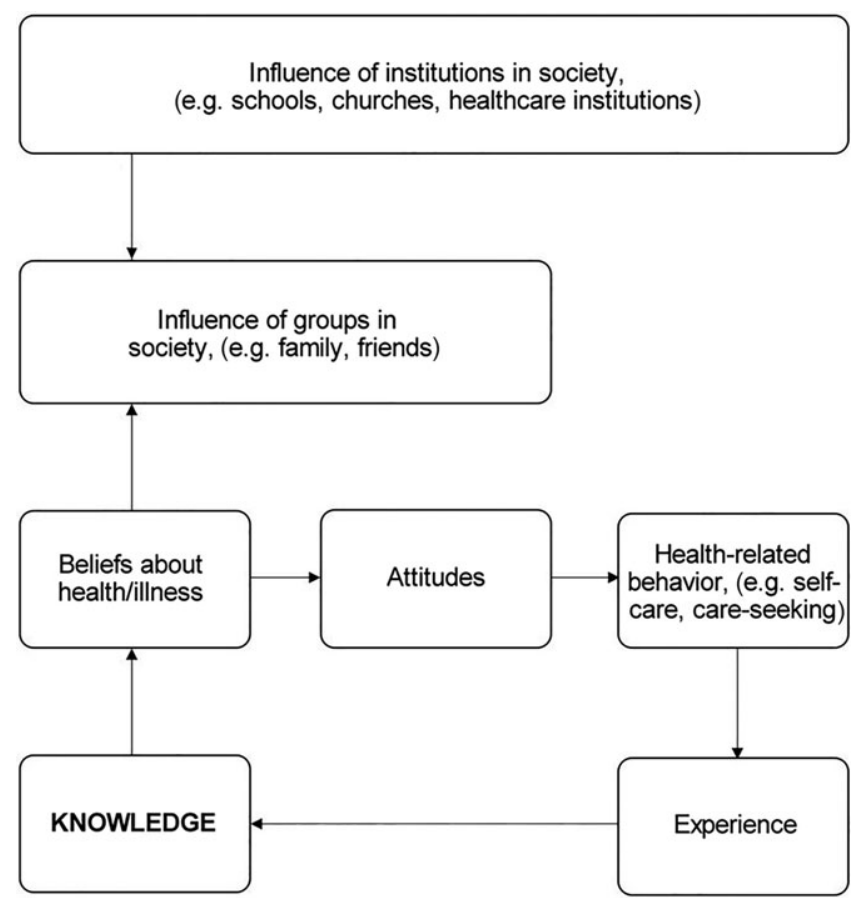

Figure 1. Theoretical framework of the education model. Health-related behavior, including self-care, is determined by beliefs about health and illness held by the individual, based on the person's knowledge and refined by experiences. Individual beliefs are culturally determined, transmitted through language and learned by socialisation in contact with others in the family, other groups and institutions in the society (e.g. schools, churches, health care institutions).

are covered. Thus, this education is individualised and person-centred, as recommended in the laws regulating healthcare in Sweden (SFS, 2014; 2017).

\section{Implementation}

The model is planned to include five sessions, each one approximately 90 min long, and the education should be completed in three months and be held at a primary health care centre. Interventions over three months have shown better outcomes than shorter ones (Attridge et al., 2014; Creamer et al., 2016). The longest improvement over time is seen in using group sessions for education only (Creamer et al., 2016). The amount of contact time to give significant effect has not been analysed, but five sessions seemed to be reasonable judging from previous studies (Hawthorne et al., 2008; Attridge et al., 2014;Creamer et al., 2016). Experiences from studies researching individual beliefs about health and illness in focus groups, the chosen educational strategy (Hjelm et al., 1999; 2003; 2005; 2013), support the number and length of sessions. Management of persons with type 2 diabetes, including diabetes education, is recommended to be held in primary health care (Socialstyrelsen, 2018; ADA, 2019) and with few exceptions previous interventions have been implemented in the community (Hawthorne et al., 2008; Attridge et al., 2014, Creamer et al., 2016).

When planning the sessions it is important that participants are selected with a view to homogeneity, so that they will feel free to share their feelings and opinions within the group (Krueger and Casey, 2015). In this model the selection criteria are: being diagnosed with and living with type 2 diabetes and practising self-management of the disease. Further, the participants should have a similar background as regards country of birth/ethnic origin and language, age and gender, as culturally appropriate health education should deliver information to same-gender groups and adapted to a particular community (Socialstyrelsen, 2012; Attridge et al., 2014).

When complex issues or sensitive topics are discussed, the focus groups should be small, with three to five participants, because small groups are easier to host and run and are comfortable for the participants (Tang and Davis, 1995; Côté-Arsenault and Morrison-Beedy, 1999; Krueger and Casey, 2015). Using a small-group design allows all the members to tell their stories in full (Choi and Rush, 2012) and enables them to learn about their health behaviours (Krueger and Casey, 2015). It is also important to be aware of language barriers in diabetes education for migrants (Choi and Rush, 2012), and therefore an interpreter should be present. This is another reason for limiting the group size. The interaction in the group is more important than the number of participants (Tang and Davis, 1995), and the moderator is the one responsible for facilitating the process of interaction (Krueger and Casey, 2015). In reality this means ensuring that all participants are involved in the discussions, and it prevents anyone from taking over. The choice of the small-group design is also supported by experiences from previous studies investigating beliefs about health and illness in migrants in the presence of an interpreter (Hjelm et al., 1999; 2003; 2005; 2013).

In this group education model the participants are recruited by telephone, by a nurse specialised in diabetes care. The interpreter, if needed, should be an authorised professional, meaning a qualified and trained person specialised in healthcare, and working in a faceto-face encounter, as recommended (Hadziabdic and Hjelm, 2013). The interpreter should be recruited from an interpreter agency and should have the competence, language/dialect, ethnic origin, religious background, gender, social group, appearance and attitude required, for the participants' needs (Hadziabdic and Hjelm, 2013).

The sessions are performed in a secluded room at a health care clinic, as the venue should be a familiar environment that is socially acceptable to the participants (Krueger and Casey, 2015). Sessions should be relaxed, with comfortable seating and some refreshments. The participants should sit in a circular arrangement with an open space in front of them to promote the interaction between them.

A particular aim of the sessions is to support the participants in developing an understanding of the complex relationship between blood glucose control and management in terms of diet, exercise and self-management, in order to promote health and prevent complications related to diabetes. Learning to be observant to changes in blood glucose and the relation between symptoms, pathophysiology and actions is crucial, and therefore knowledge from different subjects, particularly medical science and nursing science, should be integrated.

\section{Multi-professional diabetes team}

The educational model includes a multi-professional diabetes team a physician, a podiatrist, and a dietician, led by a diabetes specialist nurse (DSN) - as diabetes is a complex disease that needs to be understood and managed in a holistic way, including knowledge from different professions and subjects (Bodenheimer et al., 2002; Socialstyrelsen, 2018; ADA, 2019). The DSN has specialist competence in the subject of diabetes and diabetes care, and is also particularly trained and skilled in person-centred diabetes education (Socialstyrelsen, 2018). The DSN should attend all sessions as it 
has previously been shown to be valuable to have one person who is always present, contributing to the sense of continuity and thus security among the participants, which has a positive influence on glycaemic control (Attridge et al., 2014). A positive relation has also been found between care delivered by a DSN and glycaemic control.

\section{Framework for content}

The themes for discussion at the five sessions in this educational model are based on: (1) the Swedish national guidelines for diabetes care (Socialstyrelsen, 2018); (2) Swedish law (SFS, 2017), specifically the Health and Medical Services Act; (3) systematic literature reviews about diabetes care for migrants and ethnic minority groups (Attridge et al., 2014; Joo, 2014; Creamer et al., 2016); (4) literature about focus-group discussions (Kitzinger, 1995; Krueger and Casey, 2015); (5) nursing self-care theory (Orem, 2001); (6) previous research on individual beliefs about health and illness (Hjelm et al., 1999; 2003; 2005; 2013) and (7) a previous study showing knowledge deficits concerning diabetes and diabetes care (Pettersson et al., 2018).

The sessions (see Table 1) follow a thematic interview guide with open-ended questions. The first session is based on the participants' own individual beliefs about illness and their own thoughts about why they contracted type 2 diabetes. In addition, the participants discuss how the disease was discovered, how it might affect the body and normal glucose uptake. Finally, beliefs about future health are also discussed: how long it will persist and fears related to DM.

In the second session, the participants discuss their individual beliefs about how to achieve good glycaemic control, including the four cornerstones: food, exercise, medication and awareness/ knowledge. They also learn how to recognise changes in blood glucose control and discuss self-care measures, including the use of nature cure remedies or alternative medicine, in relation to critical situations/health problems with changed control (e.g. infections, hyper- or hypoglycaemia). A physician should also attend this session. At the third session the participants discuss their individual beliefs about why diabetes-related short- and long-term complications occur, how they affect the body and particularly how they can be prevented. A podiatrist should also attend this session, with whom the participants have the opportunity to discuss daily foot care and how to prevent 'the diabetic foot'. During the fourth session, diet and eating habits are discussed, and the participants discuss their individual beliefs about how they should eat in relation to type 2 diabetes, thus, principles for dietary adjustment. A dietician should also attend the session. The fifth and last session is planned to summarise beliefs about how to achieve good glycaemic control and the complex relation between diet, exercise, medication and awareness/knowledge. Thus the effects of exercise, diet and medication are also discussed, and how to assess blood glucose control. At this session, the whole diabetes team is present, in order to contribute to a holistic picture of the management and to answer any of the participants' questions. In addition, during the sessions, booklets are handed out in the participants' native language, concerning diabetes-related complications and self-care.

\section{Discussion}

The content of this article is unique since it describes a culturally appropriate health diabetes education model based on individual beliefs about health and illness and knowledge conducted in focus-group discussions guided by a semi-structured interview guide in five sessions, led by a diabetes specialist nurse in collaboration with a multi-professional team, and completed in three months.

Despite a previously expressed need, culturally tailored diabetes education models for migrants are lacking (Hawthorne et al., 2008; Attridge et al., 2014; Creamer et al., 2016) or have not been evaluated (Chatterjee et al., 2018). This is why the model developed here is important and aimed to fill a knowledge gap. The present model differs from previous attempts (Hawthorne et al., 2008; Attridge et al., 2014; Creamer et al., 2016) as it starts from the participants' own beliefs about health and illness, based on their knowledge. Because beliefs are culturally determined and learned by socialisation (Berger and Luckmann, 1991), the model is culturally tailored and person-centred, delivered by a multi-professional team instead of having education sessions consisting of structured lectures, where the educator, usually a healthcare professional, teaches the patient about diabetes care. Previous research has found that group-based education resulted in improvements in patients' knowledge about diabetes and glycaemic control (Hawthorne et al., 2008; SBU, 2009; Steinsbekk et al., 2012; Attridge et al., 2014; Creamer et al., 2016; Chatterjee et al., 2018; Miller et al., 2020). National guidelines for diabetes care (Socialstyrelsen, 2018) and evaluations of diabetes care (SBU, 2009; Socialstyrelsen, 2012) likewise recommend group-based education for persons with type 2 diabetes, and therefore focus-group discussions were chosen as the teaching strategy.

The interaction between the participants not only facilitates exchange of beliefs and knowledge (Krueger and Casey, 2015) but group-based education has also been found to be positive for perceived social support, which has shown positive effects on self-care in persons with type 2 diabetes (Berterö and Hjelm, 2010).

A dietician participates during one session together with the nurse specialised in diabetes care, and can give advice if needed based on participants' own eating habits linked to dietary recommendations in the national guidelines for diabetes care (Socialstyrelsen, 2018). In previous studies (Attridge et al., 2014) the cultural dietary preferences and eating habits of the target population have been discussed, based on traditional food in the participants' country of origin. This, which is not always relevant for the participants, since habits, like eating habits, may change in the new country during the acculturation process (Berry, 2005).

Beliefs about health and illness, including lay beliefs about causes of diabetes, are important cultural aspects that should be taken into account in culturally tailored education (Attridge et al., 2014). This education model is based on participants' individual beliefs about health and illness irrespective of their religion or country of origin, compared to previous studies where cultural beliefs, cultural misconceptions and myths regarding diabetes were discussed based on the participants' country of origin (Attridge et al., 2014). It is of great importance to remember that cultural representations and generalisations, such as beliefs about health and illness, can vary within the same ethnic group and thus need to be assessed individually (Hjelm et al., 1999; 2003; 2005).

The present model for group-based education, implemented with focus-group interviews as a teaching strategy is new, and the size of the groups is smaller than recommended for focus groups (three to five participants instead of six to eight) (Krueger and Casey, 2015). However, considering critical factors for the focus-group interview method, such as the use of an interpreter (Hadziabdic and Hjelm, 2013) and the complexity of the topic, a small group is preferable (Tang and Davis, 1995; CôtéArsenault and Morrison-Beedy, 1999; Krueger and Casey, 2015). The most important thing is to promote interaction between the 
participants and achieve good discussions, which is easier in a small group design (Krueger and Casey, 2015). The interaction in the groups is more important than the size of the group (Tang and Davis, 1995).

This education model is led by a nurse specialised in diabetes care who acts as a moderator, promoting interaction and discussions between the participants in the group. The diabetes specialist nurse provides support with new knowledge when knowledge gaps are found. This means that, by focussing on the participants' individual beliefs and knowledge about health and illness, that is, internal resources, the diabetes specialist nurse will use the educative and supportive nursing system in facilitating learning about diabetes and self-management, and thereby improve a person's self-agency (Orem, 2001). Further, individual members of the multi-professional team attend during the five different sessions and finally in the last session all of them attend to be able to cover different areas of diabetes management and respond to the participants' questions. Multi-professional diabetes teams involved in education have been found to contribute to significant improvement in glycaemic control and knowledge about diabetes and are therefore recommended (Attridge et al., 2014: Creamer et al., 2016).

The education model described here has been developed to achieve the goal of a culturally appropriate programme, which is to develop culturally and linguistically appropriate services that function within the context of the cultural beliefs, behaviour and needs presented by an ethnic group (Attridge et al., 2014). Since each culture has distinct values and beliefs concerning health, health behaviours and eating practices, culturally appropriate education programmes are necessary to help individuals adopt dietary modifications relevant to their cultural preferences (Auslander et al., 2002). But most importantly, this education is based on the participants' individual beliefs about health and illness, determined by cultural background (Hjelm et al., 2003; 2005; 2013), and planned to improve knowledge about type 2 diabetes and thus increase self-care and improve health.

\section{Conclusion}

It has been found that migrants have difficulties assimilating knowledge about diabetes in existing education models offered by health care. Therefore a culturally appropriate diabetes education model has been developed, conducted in a focus-group discussion based on the participants' individual beliefs about health and illness and their knowledge about diabetes and diabetes care and experiences of self-care. The education model is therefore both individually and culturally tailored and intended to improve knowledge about type 2 diabetes among migrants and thus increase self-care behaviour and improve health.

\section{Strengths and limitations}

It is a strength that many aspects, from both a scientific and clinical perspective, and a theoretical base were considered when this education model was developed in collaboration with a multi-professional diabetes team. Further, this education model ought to be appropriate for several population groups considering that it is based on the participants' individual beliefs about health and illness and can be implemented at different phases during the illness trajectory and thus be delivered at various times. However, one limitation might be that the model is not tested yet, which is the next step in the research process. Then an evaluation from the users' perspective will also be included to further revise the model.
Acknowledgments. We are grateful to Dr Alan Crozier for review of the language. We would like to thank the diabetes care team at the health care centre for excellent collaboration in developing the model for diabetes education. This work was supported by grants from The Swedish Diabetes Association (Svenska Diabetesförbundet).

Financial Support. This work was supported by grants from The Swedish Diabetes Association (Svenska Diabetesförbundet).

Conflicts of Interest. None.

\section{References}

American Diabetes Association (ADA) (2019) Standards of medical care in diabetes-2019 abridged for primary care providers. Clinical Diabetes 37, 11-34. doi: 10.2337/cd18-0105

Attridge M, Creamer J, Ramsden M, Cannings-John $\mathrm{R}$ and Hawthorne $\mathrm{K}$ (2014) Culturally appropriate health education for people in ethnic minority groups with type 2 diabetes mellitus. Cochrane Database of Systematic Reviews 9, CD006424.

Auslander W, Haire-Joshu D, Houston C, Chaie-Won R and Williams JH (2002) A controlled evaluation of staging dietary patterns to reduce the risk of diabetes on African-American women. Diabetes Care 25, 809-814.

Bandura A (1995) Exercise of personal and collective efficacy in changing societies. In Bandura A, editor, Self-efficacy in changing societies. New York: Cambridge University Press.

Berger P and Luckmann T (1991) The social construction of reality: a treatise in the sociology of knowledge. London: Penguin Books.

Berry JW (2005) Acculturation: living successfully in two cultures. International Journal of Intercultural Relations 29, 697-712.

Berterö C and Hjelm K (2010) Social support as described by foreign-born persons diagnosed with type 2 diabetes mellitus and living in Sweden. Nursing \& Health Sciences 12, 507-514.

Bodenheimer T, Wagner E and Grumsback K (2002) Improving primary care for patients with chronic illness: the chronic care model. Journal of the American Medical Association 288, 1775-1779.

Chatterjee S, Davies M, Stribling B, Farooqi A and Khunti K (2018) Realworld evaluation of the DESMOND type 2 diabetes education and self-management programme. Practical Diabetes 35, 19-22a.

Cho NH, Shaw JE, Karuranga S, Huang Y, da Rocha Fernandes JD, Ohlrogge AW and Malanda B (2018) IDF diabetes atlas: global estimates of diabetes prevalence for 2017 and projections for 2045. Diabetes Research and Clinical Practice 138, 271-281. doi: 10.1016/j.diabres.2018. 02.023

Choi SE and Rush EB (2012) Effect of a short-duration, culturally tailored, community-based diabetes self-management intervention for Korean immigrants: a pilot study. Diabetes Education 38, 377-385. doi: 10.1177/ 0145721712443292

Coppola A, Sasso L, Bagnasco A, Guistina A and Gazzaruso C (2016) The role of patient education in the prevention and management of type 2 diabetes: an overview. Endocrine 53, 18-27. doi: 10.1007/s12020-015-0775-7

Côté-Arsenault D and Morrison-Beedy D (1999) Practical advice for planning and conducting focus groups. Nursing Research 48, 280-283.

Creamer J, Attridge M, Ramsden R, Cannings-John R and Hawthorne $K$ (2016) Culturally appropriate health education for type 2 diabetes in ethnic minority groups: an updated Cochrane Review of randomized controlled trials. Diabetic Medicine 33, 169-183. doi: 10.1111/dme.12865

Deakin TA, Cade JJ, Williams R and Greenwood DC (2006) Structured patient education: the diabetes X-PERT Programme makes difference. Diabetic Medicine 23, 944-954.

Glanz K, Rimer B and Viswanath K (2008) Health behaviour and health education: theory, research, and practice, fourth edition. San Francisco, CA: Jossey-Bass.

Hadziabdic E and Hjelm K (2013) Working with interpreters: practical advice for use of an interpreter in healthcare. International Journal of Evidence Based Healthcare 11, 69-76.

Hawthorne K, Robles Y, Cannings-John R and Edwards A (2008) Culturally appropriate health education for type 2 diabetes mellitus in ethnic minority 
groups. Cochrane Database Systematic Review 16, CD006424. doi: 10.1002/ 14651858.CD006424.pub2

Hjelm K, Bard K and Apelqvist J (2013) Beliefs about health and illness in Latin-American Migrants with diabetes living in Sweden. The Open Nursing Journal 7, 57-65.

Hjelm K, Bard K, Nyberg P and Apelqvist J (2003) Religious and cultural distance in beliefs about health and illness in diabetic women of different origin living in Sweden. International Journal of Nursing Studies 40, 627-643.

Hjelm K, Bard K, Nyberg P and Apelqvist J (2005) Beliefs about health and illness in men with diabetes mellitus of different origin living in Sweden. Journal of Advanced Nursing 1, 47-59.

Hjelm K, Nyberg P, Isacsson A and Apelqvist J (1999) Beliefs about health and illness essential for self-care practice: a comparison of migrant Yugoslavian and Swedish diabetic females. Journal of Advanced Nursing 30, 1147-1159.

Hörnsten Å and Graneheim UH (2009) A lesson to learn-patients' critiques of diabetes nursing. The Internet Journal of Advanced Nursing Practice 11. http://ispub.com/IJANP/11/1/4278

International Diabetes Federation (IDF) (2017) Diabetes atlas, eighth edition. Brussels: IDF. https://www.idf.org/e-library/epidemiology-research/ diabetes-atlas/134-idf-diabetes-atlas-8th-edition.html

Joo JY (2014) Effectiveness of culturally tailored diabetes interventions for Asian immigrants to the United States. The Diabetes Educator 40, 605615. doi: 10.1177/0145721714534994

Jutterström L, Hörnsten Å, Sandström H, Stenlund H and Isaksson U (2016) Nurse-led patient-centered self-management support improves HbAlc in patients with type 2 diabetes - a randomized study. Patient Education and Counselling 99, 1821-1829. doi: 10.1016/j.pec.2016.06.016

Kitzinger J (1995) Qualitative research: introducing focus groups. British Medical Journal 311, 299-302.

Knight KM, Dornan T and Bundy C (2006) The diabetes educator: trying hard but must concentrate on behavior. Diabetic Medicine 23, 485-501.

Krueger R and Casey M (2015) Focus groups: a practical guide for applied research, fifth edition. Thousand Oaks, CA: Sage publications.

Leininger M and McFarland MR (2006). Culture care diversity and universality: a worldwide nursing theory, second edition. London: Jones and Bartlett.

Miller V, Davies M, Etherton-Beer C, McGough S, Schofield D, Jensen J and Watson N (2020) Increasing patient activation through diabetes self-management education: outcomes of DESMOND in regional Western Australia. Patient Education and Counseling 103, 848-853.

Montesi L, Caletti MT and Marchesin G (2016) Diabetes in migrants and ethnic minorities in a changing world. World Journal of Diabetes 7, 34-44. doi: 10.4239/wjd.v7.i3.34
Orem DE (2001). Nursing: concepts of practice, sixth edition. St. Louis, MO: Mosby-Year Book Inc.

Pettersson S, Hadziabdic E, Marklund H and Hjelm K (2018) Lower knowledge about diabetes among foreign-born compared to Swedish-born persons with diabetes_a descriptive study. Nursing Open 2, 367-376. doi: 10.1002/nop2.217

Richards D (2015) The complex interventions framework. In Rahm Hallberg I and Richards D, editors. Complex interventions in health: an overview of research methods. London and New York: Routledge.

Roger C and Freiberg HJ (1994). Freedom to learn, 3rd edition. New York: Macmillan.

Rosenstock IM, Strecher VJ and Becker MH (1988) Social learning theory and the health belief model. Health Education Quarterly 11, 403-418.

SBU (Swedish Council on Health Technology Assessment) (2009) Summary and conclusions of the SBU report: patient education in managing diabetes: $a$ systematic review. Stockholm: Swedish Council on Health Technology Assessment (SBU).

SFS (2014) Patientlag. (The Swedish Patient Act). SFS 2014:821. Stockholm: Svensk Författningssamling.

SFS (2017) Hälso- och sjukvårdslag. (The Swedish Health and Medical Services Act). SFS 2017:30. Stockholm: Svensk författningssamling.

Socialstyrelsen (2012). Nationell utvärdering 2011-Diabetesvård. Landstingen och kommunernas insatser. (National evaluation 2011 - Diabetes care, the county councils and the municipalities responsibility). Retrieved 15 September 2019 from http://www.socialstyrelsen.se/Lists/Artikelkatalog/ Attachments/18521/2012-1-1.pdf

Socialstyrelsen (2018) Nationella riktlinjer för diabetesvården 2018-Stöd för styrning och ledning. The National Board of Health and Welfare. National Guidelines for Diabetes Care 2018 - Support for steering and management). Retrieved 1 October 2019 from https:/www.socialstyrelsen.se/Lists/ Artikelkatalog/Attachments/20633/2017-5-31.pdf

Statistiska Centralbyrån (2018). Tabeller över Sveriges befolkning (Statistics Sweden. 2018. Tables on the population in Sweden 2018). Örebro: Statistiska centralbyrån. Retrieved 1 December 2018 from http://www.scb.se

Steinsbekk A, Rygg L, Lisulo M, Rise M and Fretheim A (2012) Group based diabetes self-management education compared to routine treatment for people with type 2 diabetes mellitus: a systematic review with meta-analysis. BMC Health Services Research 12, 213.

Tang KC and Davis A (1995) Critical factors in the determination of focus group size. Family Practice 12, 474-475.

Testa R, Bonfigli AR, Genovese S and Ceriello A (2015) Focus on migrants with type 2 diabetes mellitus in European countries. International Emergency Medicine 11, 319-326. doi: 10.1007/s11739-015-1350-1 